\title{
Pore Changes in Purple Mudstone Based on the Analysis of Dry-Wet Cycles Using Nuclear Magnetic Resonance
}

\author{
Chen Dang $\mathbb{D}^{1,2,3}$ Zhili Sui, $^{4}$ Xiuyuan Yang, ${ }^{5,6}$ and Zhenlong Ge ${ }^{1,2,3}$ \\ ${ }^{1}$ China Coal Technology and Engineering Group, Xi'an 710054, China \\ ${ }^{2}$ Shaanxi Provincial Key Laboratory of Geological Support for Coal Green Exploitation, Xi'an, Shaanxi Province, China \\ ${ }^{3}$ Key Laboratory of Coal Resources Exploration and Comprehensive Utilization, Ministry of Land and Resources, Xi'an, \\ Shaanxi Province, China \\ ${ }^{4}$ Urban Construction School, Beijing City University, Beijing, China \\ ${ }^{5}$ School of Resources and Geosciences, China University of Mining and Technology, Xuzhou 221116, Jiangsu, China \\ ${ }^{6}$ Center for Hydrogeology and Environmental Geology, China Geological Survey, Baoding 071051, Hebei, China
}

Correspondence should be addressed to Chen Dang; dangchenxust@163.com

Received 1 March 2021; Revised 6 July 2021; Accepted 3 December 2021; Published 25 January 2022

Academic Editor: Zengshun Chen

Copyright (C) 2022 Chen Dang et al. This is an open access article distributed under the Creative Commons Attribution License, which permits unrestricted use, distribution, and reproduction in any medium, provided the original work is properly cited.

The study on the change of rock pore structure during the weathering of purple mudstone is of guiding significance to the stability of the bank slope of the three gorges reservoir. In this paper, the pore changes in the wet and dry circulation of purple mudstone in the three gorges reservoir area are studied by means of nuclear magnetic resonance (NMR). The results show that the simulated weathering of wet and dry circulation has a great influence on the purple mudstone. With an increase in the number of dry-wet cycles, the purple mudstone pore volume ratio significantly changed. Originally, it consisted of a small pore structure with a single pore diameter of $0.01-0.1 \mu \mathrm{m}$ and changed to a variety of pore structures with various pore diameters of $0.001-100 \mu \mathrm{m}$. With the increase in the number of dry-wet cycles, the micropores $(0.001-0.1 \mu \mathrm{m})$ were transformed into macropores $(0.1-1 \mu \mathrm{m})$. The area of the second peak of the three samples (large pores $0.1-1 \mu \mathrm{m}$ ) increased from $0.9413,0.9974$, and 0.6779 to $0.9871,1.1498$, and 0.9901 , respectively.

\section{Introduction}

Owing to the requirements of engineering construction projects, including tunnels, mining, and rock excavations, current research on the effects of water-rock chemistry on the physical and mechanical properties of rock masses has become a hotspot for geotechnical engineering [1]. The drywet cycle has a great influence on rock properties and the geological environment. Water storage and drainage of the Three Gorges Dam on the Yangtze River, groundwater seepage, and seasonal precipitation cause changes in reservoir water levels, and the rock mass is periodically in a drywet state. Therefore, landslides, collapses, and deformation of the dam foundation are often triggered. In response to the problems associated with dry-wet cycles, a lot of research has been undertaken. Changes in physical properties have been used to evaluate rock deterioration and damage after dry-wet cycles. Using Yangtze River water and distilled water to study the effects of the dry-wet cycles, these authors compared the rock deterioration in these two cases and concluded that the degradation effect of distilled water on sandstone was lower than that of river water, thus providing a more accurate method for evaluating geological disasters and engineering faults [2]. River water is not composed of a single solution; thus, the combination of different anions and cations in the water causes the rocks to be under different water-rock interaction conditions. Testing the dry-wet cycle under acidic conditions, the corrosion of underground engineering by acid rain has been simulated, and the changes in the microscopic pore structure of sandstone under the combined effect of an acidic environment and dry-wet cycle were examined to provide a reference for the safety and 
durability of underground engineering [3]. The pore type and structure, as well as the porosity and permeability of coal have been studied previously by designing nuclear magnetic resonance (NMR) experiments to better estimate the permeability of coal [4]. The damage characteristics of the limestone mesostructure under different water chemistry conditions were studied, using the change in porosity to evaluate the degree of damage and thus creating a damage evolution model for rocks [5]. Li et al. [6] studied the changes in the cement composition of sandstone under different $\mathrm{pH}$ and acidic environments, and the chemical reaction rate was summarised as the damage factor of the rock corrosion process. A chemical damage model that can be used for the prediction of the mechanical properties of acid-corroded rocks during different periods was established. Previous studies have shown that an increase in the number of wet and dry cycles aggravates rock damage, creating an increase in the effective pores [7-15]. Many researchers have conducted laboratory tests on reservoir rocks. By controlling the wet and dry conditions, including the chemical composition, temperature, and timing of the aqueous solution, the physical and mechanical properties of bank rocks after wet-dry cycles have been tested, with the test results providing a reliable basis for engineering construction projects [16-18].

However, few studies have applied NMR methods to purple mudstones after wet-dry cycles. Owing to the advantages of NMR technology, including being convenient, quick, and nondestructive, such technology has been widely utilised in many disciplines including medicine, civil engineering, geology, geophysics, biological sciences, and agricultural sciences [19-24]. In particular, NMR technology has been utilised in the field of geology to test the pore characteristics of rocks. In the traditional dry-wet cycle experiments involving rocks, the compressive and tensile strengths and the micropore structure of the rocks have been used to evaluate the physical and mechanical properties. The change in porosity can be used to evaluate the degree of damage and a damage evolution model of the rock established. However, the sample is discarded after one test using constant-pressure mercury injection, whereas the NMR method used to study the pore structure is fast and repeatable and does not damage the sample.

Considering the new types of landslides caused by the storage and release of the Yangtze River Three Gorges Dam, the present study focused on the variation of the internal pore characteristics of purple mudstone on the bank slopes of the Three Gorges Reservoir under multiple dry-wet cycles. The research results provide a theoretical basis for the dry-wet multicycle physical-mechanical experimental evaluation project of a typical slope formation rock and soil and provide a basis for studying the formation of landslides in the Three Gorges area.

\section{Materials and Methods}

2.1. Rock Sample Preparation. The present study collected purple mudstones from the bank slopes of the Yangtze River in Wanzhou District, Chongqing, China. The geographical and sampling locations are shown in Figure 1. The mineral properties of the purple mudstone samples are shown in
Table 1. Table 2 shows the analysis results from the purple mudstone energy dispersive spectrometer (EDS) tests. The main mineral component was quartz with approximately $13 \%-15 \%$ and also contained a small amount of feldspar, rock debris, and mica. The diameter of the mineral particles was $0.25-0.50 \mathrm{~mm}$, and they were irregularly round. A total of three purple mudstone samples were prepared for the analysis, namely, purple mudstone samples no. 1, 2, and 3 .

2.2. Test Equipment and Methods. In the present study, a Niu Man MacroMR low-field NMR instrument was used to test the porosity changes of the purple mudstones under multiple dry and wet cycle periods. The sample was placed in a blast drying box to dry (temperature $60^{\circ} \mathrm{C}$, time $6 \mathrm{~h}$ ), and then the sample was placed in a vacuum saturation tank to be saturated (vacuum for $2 \mathrm{~h}$, soak for $24 \mathrm{~h}$ ). This constituted the drying and wetting cycles. The saturated sample was removed from the tank, the surface water wiped off, and the sample was sealed with two layers of plastic wrap to prevent moisture from dissipating and any external interference. After each cycle, the prepared sample was placed into the NMR tester. The purple mudstone samples no. 1, 2, and 3 were destroyed after cycling for 8,7 , and 5 times, respectively. The detailed test process is shown in Figure 2.

\section{Experimental Results and Analysis}

Nuclear magnetic resonance causes hydrogen protons to spin themselves in a magnetic field to align with the direction of the field. Then, the magnetic field changes direction and turns off again, causing the hydrogen proton to return to its original state. In this process, the induction signal received by the coil changes. This process is called relaxation $[25,26]$. The transverse relaxation time $\mathrm{T} 2$ is the time constant for the exponential decay of the spin echo amplitude of a single pore body. For porous systems such as porous networks, exponential decay is the sum of individual decays. Using inversion processing technology, the original attenuation curve can be fitted to T2 spectrum. Most NMR interpretation and rock physical parameter estimation, such as porosity, pore size distribution, and permeability, are based on this T2 spectrum [27-29].

Adding a corresponding magnetic field to the outside of the purple mudstone sample obtained the relaxation rate and intensity of the fluid hydrogen nuclei in the pores of the sample. From this analysis, the pore fracture state of the purple mudstone sample was obtained. Determining the $T_{2}$ peak and distribution interval of the relaxation time is the main method used in NMR testing. In addition, the superposition of the three mechanisms of lateral volume relaxation, lateral surface relaxation, and diffusion relaxation constitutes the total lateral relaxation rate:

$$
\frac{1}{T_{2}}=\frac{1}{T_{2 B}}+\frac{1}{T_{2 S}}+\frac{1}{T_{2 D}},
$$

where $T_{2}$ is the total relaxation time; $T_{2 \mathrm{~B}}$ is the volume relaxation time; $T_{2 S}$ is the surface relaxation time; and $T_{2 \mathrm{D}}$ is the diffusion relaxation time. 


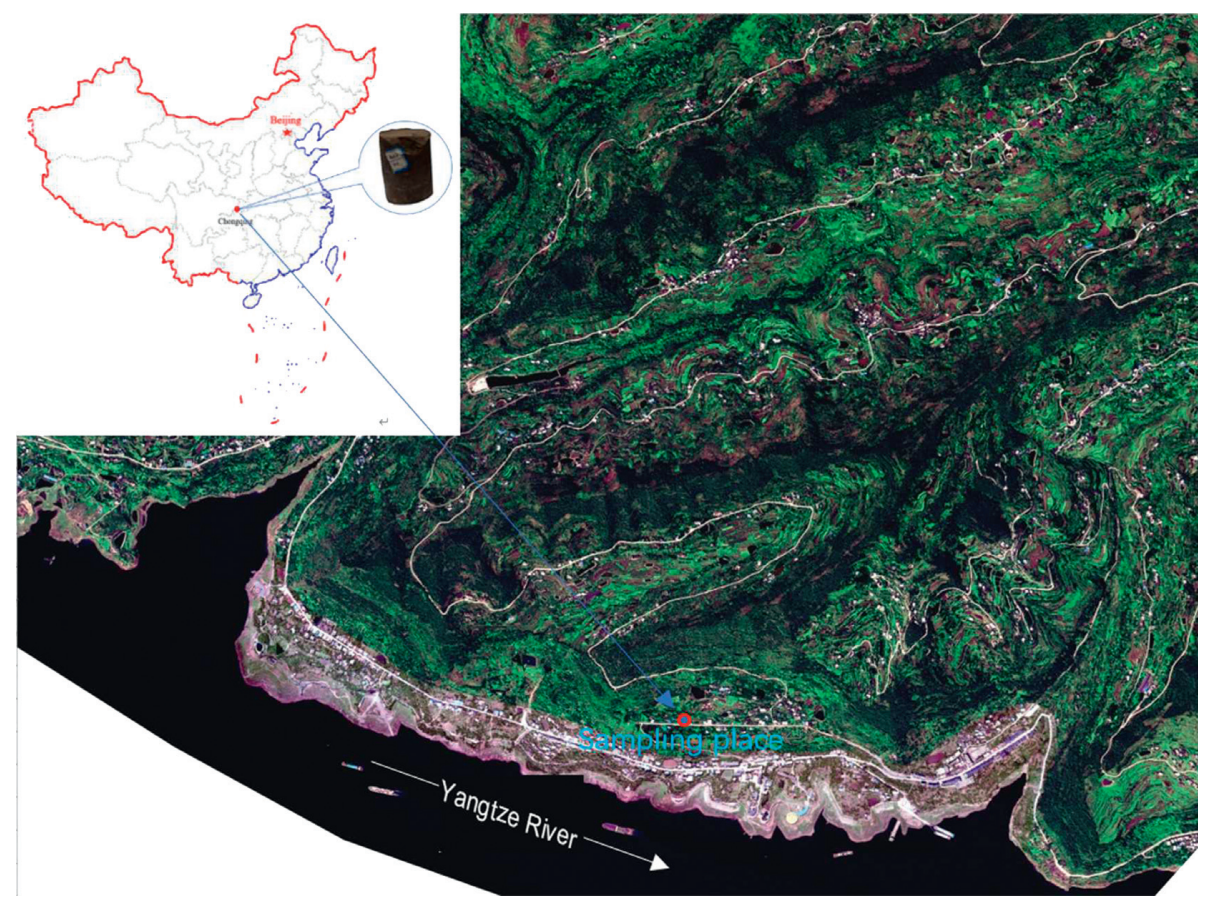

FIGURE 1: Sketch of the geographical position of the rock sample.

TABLE 1: X-ray diffraction (XRD) mineral composition analysis results.

\begin{tabular}{|c|c|c|c|c|c|c|c|c|c|}
\hline \multirow{3}{*}{ Rock samples } & \multicolumn{9}{|c|}{ Mineral composition } \\
\hline & \multicolumn{5}{|c|}{ X-ray powder diffraction (mineral composition) } & \multicolumn{4}{|c|}{$\begin{array}{l}\text { Directional tablet (in terms of } 100 \% \text { of total clay } \\
\text { mineral) }\end{array}$} \\
\hline & $\begin{array}{l}\text { Quartz } \\
(\%)\end{array}$ & $\begin{array}{c}\text { Feldspar } \\
(\%)\end{array}$ & $\begin{array}{c}\text { Calcite } \\
(\%)\end{array}$ & $\begin{array}{c}\text { Hematite } \\
(\%)\end{array}$ & $\begin{array}{c}\text { Total volume of } \\
\text { clay minerals (\%) }\end{array}$ & $\begin{array}{c}\text { Montmorillonite } \\
(\%)\end{array}$ & $\begin{array}{c}\text { Chlorite } \\
(\%)\end{array}$ & $\begin{array}{l}\text { Illite } \\
(\%)\end{array}$ & $\begin{array}{c}\text { Kaolinite } \\
\text { (\%) }\end{array}$ \\
\hline $\begin{array}{l}\text { Purple mudstone } \\
\text { sample no. } 1\end{array}$ & 13 & 3 & 3 & 2 & 79 & 10 & 15 & 70 & 5 \\
\hline $\begin{array}{l}\text { Purple mudstone } \\
\text { sample no. } 2\end{array}$ & 12 & 6 & 3 & 2 & 77 & 10 & 15 & 70 & 5 \\
\hline $\begin{array}{l}\text { Purple mudstone } \\
\text { sample no. } 3\end{array}$ & 15 & 5 & 6 & 2 & 72 & 15 & 20 & 60 & 5 \\
\hline
\end{tabular}

TABLE 2: EDS major element ratio analysis results.

\begin{tabular}{|c|c|c|c|c|c|c|c|c|c|c|}
\hline \multirow{2}{*}{ Rock samples } & \multicolumn{10}{|c|}{ Element type and content (\%) } \\
\hline & $\mathrm{C}$ & $\mathrm{O}$ & $\mathrm{Na}$ & $\mathrm{Mg}$ & $\mathrm{Al}$ & $\mathrm{Si}$ & S & $\mathrm{K}$ & $\mathrm{Ca}$ & $\mathrm{Fe}$ \\
\hline Purple mudstone sample no. 1 & 21.04 & 43.00 & 1.83 & 0.82 & 6.48 & 18.23 & 0.07 & 1.98 & 4.70 & 1.86 \\
\hline Purple mudstone sample no. 2 & 14.64 & 52.02 & 0.61 & 1.47 & 5.71 & 18.18 & 0.07 & 1.41 & 4.06 & 1.82 \\
\hline Purple mudstone sample no. 3 & 15.36 & 53.72 & 0.76 & 1.20 & 5.04 & 18.45 & 0.05 & 1.21 & 2.61 & 1.60 \\
\hline
\end{tabular}

$$
\frac{1}{T_{2}}=\rho_{2}\left(\frac{S}{V}\right)
$$

where $S$ is the rock pore surface area; $V$ is the rock pore volume; and $\rho_{2}$ is the transverse surface relaxation strength of the rock (i.e. a constant). Equation (2) shows that the pore size of the rock is proportional to the surface relaxation time, i.e., as the pore size increases, the relaxation time increases accordingly. The $T_{2}$ spectrum was obtained by performing
NMR tests on the purple mudstone samples with different numbers of dry and wet cycles. However, the shape and volume of the purple mudstone samples changed greatly during the dry-wet cycles and the $T_{2}$ spectrum had no reference significance. Therefore, the $T_{2}$ spectrum data was converted (i.e., the signal amplitude value corresponding to each $T_{2}$ time was divided by the total signal amplitude value) to obtain a pore volume ratio map and thus a different pore size development for each sample (Figure 3). 


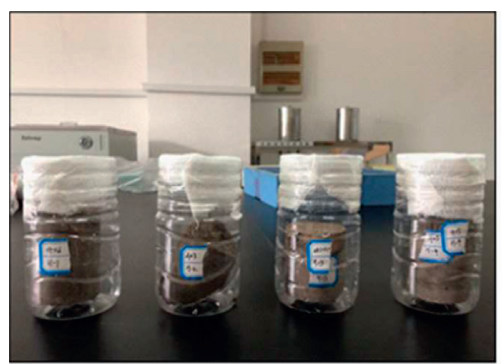

Purple mudston sample
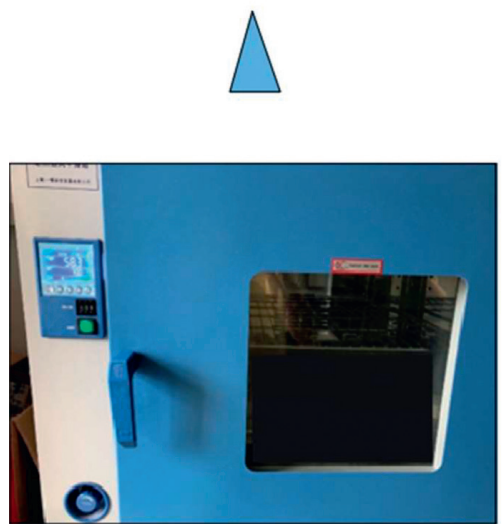

Drying treatment

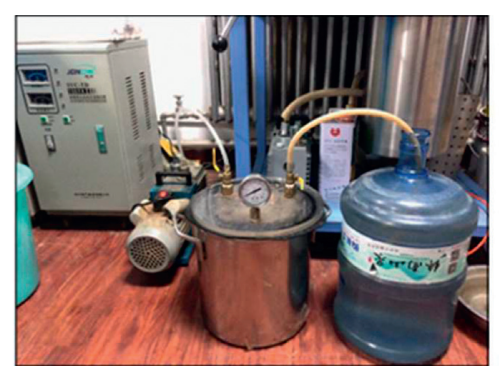

Wetting treatment
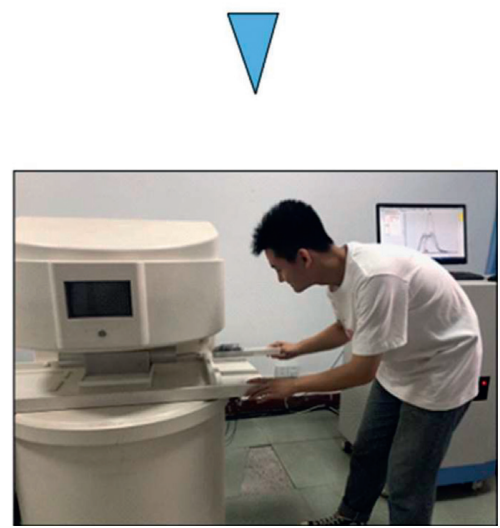

NMR test

Figure 2: Experimental flow chart.

$$
\frac{s}{v}=\frac{F_{s}}{r}
$$

where $F_{S}$ is the shape factor; $r$ is the size of the hole. According to equations (2) and (3), it can be concluded that

$$
T_{2}=\frac{r}{\rho_{s} F_{s}} \text {. }
$$

So, the linear relationship between them is as follows:

$$
r=C T_{2} \text {. }
$$

Hole size can be measured by HPMI method, $C=\rho_{S} \mathrm{~F}_{S}, \mathrm{C}$ can be calculated by linear regression [30-32].

$$
\sigma=\frac{\sqrt{\sum_{2}^{n} \omega(r(i))\left[r(i)-C T_{2}(i)\right]^{2}}}{\sqrt{\sum_{2}^{n} \omega(r(i))}}
$$

$\sigma$ is the total error in the formula. In order to choose the most accurate $\mathrm{C}$ value, you must minimize sigma. $\omega(r(i))$ is the increment frequency of pore size. So, $T_{2}$ and PTSD can be switched back and forth (5). $F_{S}$ is pore shape factor (the rock pore structure can be regarded as a tubular model, where $F_{S}=2$ ). This is the result of averaging the coefficients after each cycle to minimize the total error $\sigma$ of the linear conversion. If different spaces are filled with water, then $T_{2}$ will vary depending on the size of the space. The more water you fill the space, the greater $T_{2}$ is going to be. Therefore, equations (1)-(6) can obtain the distribution map of pore size of rock.
The pore volume ratio in the purple mudstone samples varied with the sample pore size in the different samples and dry-wet cycles. When the dry and wet cycle $N_{\mathrm{C}}$ was 1 , the purple mudstone sample nos. 1, 2, and 3 all showed single peaks of $14.0287 \%, 14.7056 \%$, and $13.52152 \%$, respectively. With an increase in the number of dry-wet cycles, the pore sizes of sample nos. 1,2 , and 3 increased from $0.0341-$ $0.0682 \mu \mathrm{m}, 0.0318-0.0594 \mu \mathrm{m}$, and $0.0318-0.0636 \mu \mathrm{m}$ to $0.0052-43.4224 \mu \mathrm{m}, \quad 0.0064-28.6292 \mu \mathrm{m}$, and $0.0040-$ $32.8935 \mu \mathrm{m}$, respectively. As the number of dry-wet cycles increased, the pore volume ratio of the purple mudstone changed from a single peak to a camel-shaped double peak with a corresponding change in the sample pore diameter. In the camel-shaped doublet, the area of the first peak (corresponding to a pore size of $0.001-0.1 \mu \mathrm{m}$ ) of sample nos. 1 , 2 , and 3 decreased from $0.1277,0.1181$, and 0.1376 to 0.1209 , 0.1047 , and 0.1245 , respectively. In the camel-shaped doublet, the area of the second peak of the three samples (with a corresponding pore diameter of $0.1-1 \mu \mathrm{m}$ ) increased from $0.9413,0.9974$, and 0.6779 to $0.9871,1.1498$, and 0.9901 , respectively. In general, as the number of wet and dry cycles increased, the proportion of micropores with a pore diameter of $0.001-0.1 \mu \mathrm{m}$ decreased compared to the total pore diameter and the large pores with a pore size of $0.1-1 \mu \mathrm{m}$ increased compared to the proportion of total pores. The details of each cycle are shown in Table 3.

The area of the first peak of the three purple mudstone samples decreased overall, whereas the peak areas of the second peak increased overall. However, there were fluctuations in the fourth and fifth cycles (Table 3). First, the purple mudstone samples became weathered and 


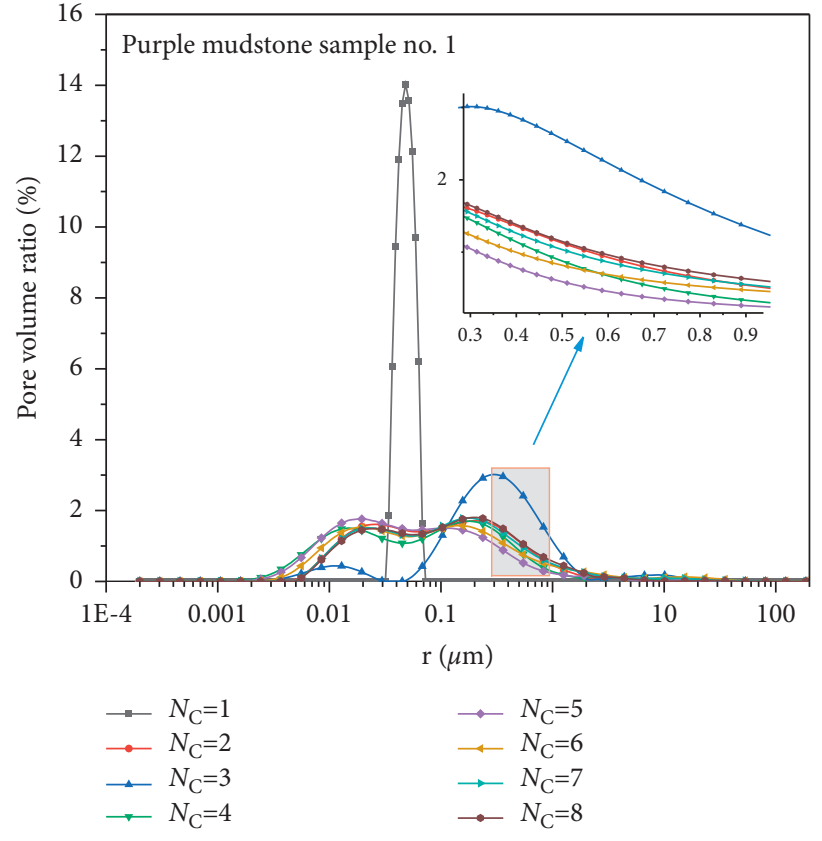

(a)

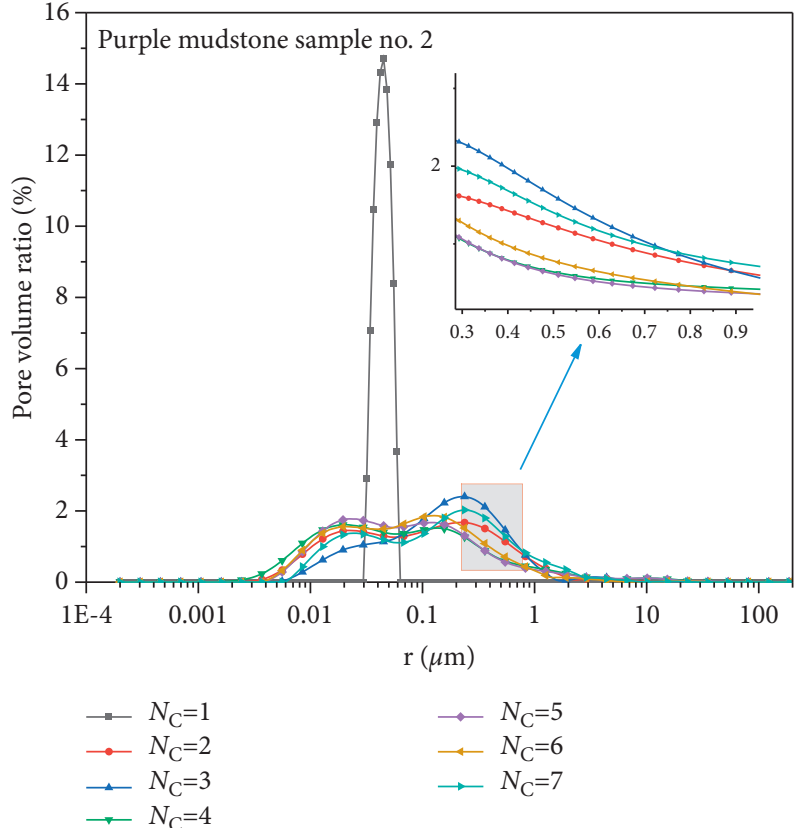

(b)

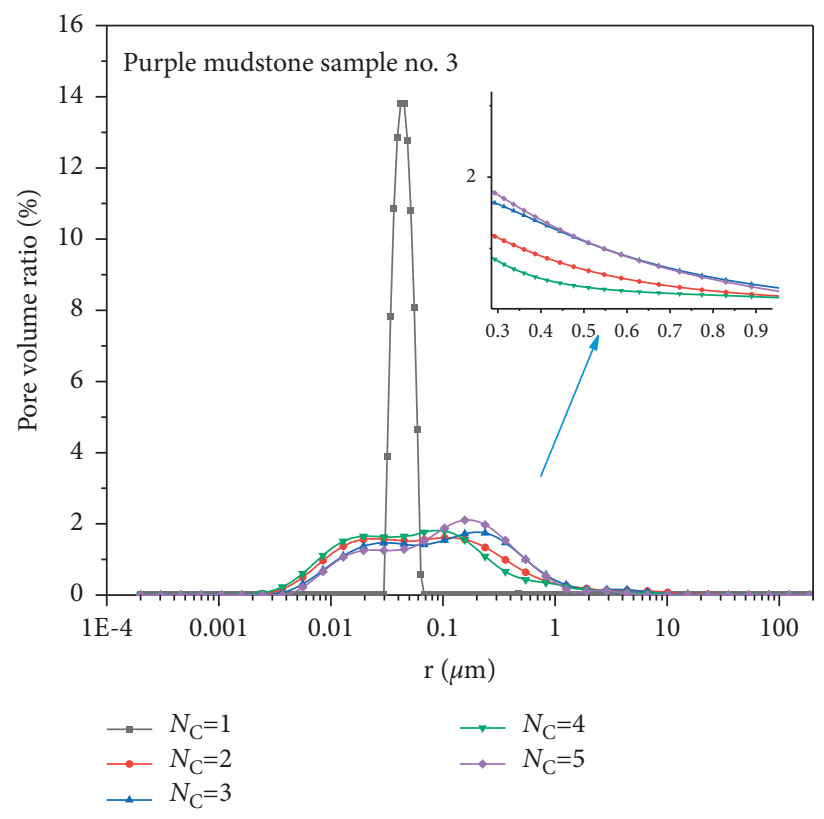

(c)

Figure 3: Proportional distribution of the whole volume: (a) sample no. 1; (b) sample no. 2; (c) sample no. 3.

disintegrated during the wet and dry cycles. After the sample was full, only the remaining intact blocks were removed for testing (Figure 4). Second, mudstone deposits were observed in the vacuum saturation tank before the fourth cycle. Mudstone adheres to the surface of the sample, making the water absorption incomplete; therefore, the measured signal amplitude was smaller than normal. Thus, the measured value of the proportion of large holes was smaller than the actual value, and the measured value of the proportion of small holes was larger than the actual value.
It can be seen from Figure 5 that, with the increase in the number of wet and dry cycles, the change of porosity presents a three-stage trend of increase-decrease-increase. The number of cycles $1-3$ is stage I, and the porosity increases sharply. The three samples increased to $24.59 \%$, $25.59 \%$, and $24.25 \%$, respectively. In stage II, the porosity begins to decrease. The porosity of the three samples dropped to $15.49 \%, 17.99 \%$, and $22.59 \%$ at the end of this stage. In stage III, porosity increases again. Each increase in porosity will cause the sample to peel off and collapse, which causes the porosity of the sample to drop to a value that will 
TABle 3: Peak area corresponding to the dry and wet cycle periods.

\begin{tabular}{|c|c|c|c|c|c|c|}
\hline \multirow{2}{*}{$\begin{array}{l}\text { Cycles } \\
\text { Rock } \\
\text { samples }\end{array}$} & \multicolumn{3}{|c|}{ The area of the first peak } & \multicolumn{3}{|c|}{ Second peak area } \\
\hline & $\begin{array}{l}\text { Purple mudstone } \\
\text { sample no. } 1\end{array}$ & $\begin{array}{l}\text { Purple mudstone } \\
\text { sample no. } 2\end{array}$ & $\begin{array}{l}\text { Purple mudstone } \\
\text { sample no. } 3\end{array}$ & $\begin{array}{l}\text { Purple mudstone } \\
\text { sample no. } 1\end{array}$ & $\begin{array}{l}\text { Purple mudstone } \\
\text { sample no. } 2\end{array}$ & $\begin{array}{l}\text { Purple mudstone } \\
\text { sample no. } 3\end{array}$ \\
\hline$N_{\mathrm{c}}=2$ & 0.1377 & 0.1181 & 0.1376 & 0.9413 & 0.9974 & 0.6779 \\
\hline$N_{\mathrm{c}}=3$ & 0.0328 & 0.1062 & 0.1247 & 1.9067 & 1.2961 & 0.9315 \\
\hline$N_{c}=4$ & 0.1141 & 0.1294 & 0.1519 & 0.7833 & 0.6520 & 0.5445 \\
\hline$N_{\mathrm{c}}=5$ & 0.1383 & 0.1420 & 0.1245 & 0.5855 & 0.6446 & 0.9901 \\
\hline$N_{c}=6$ & 0.1224 & 0.1403 & - & 0.7581 & 0.7608 & - \\
\hline$N_{\mathrm{c}}=7$ & 0.1209 & 0.1047 & - & 0.9166 & 1.1498 & - \\
\hline$N_{\mathrm{c}}=8$ & 0.1208 & - & - & 0.9871 & - & - \\
\hline
\end{tabular}

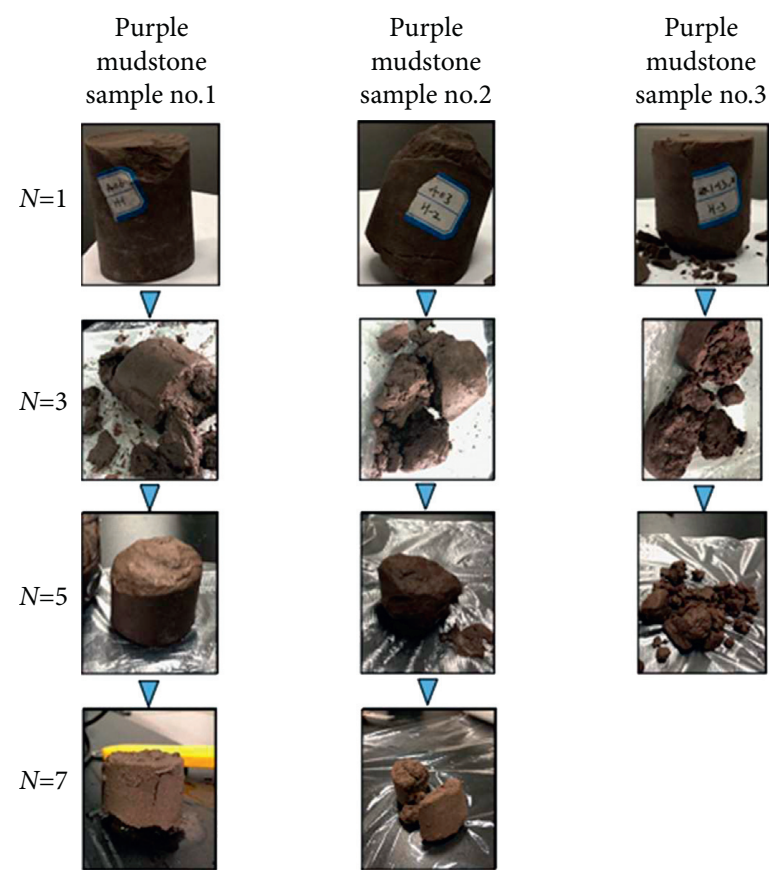

FIgURE 4: Rock sample failure process.

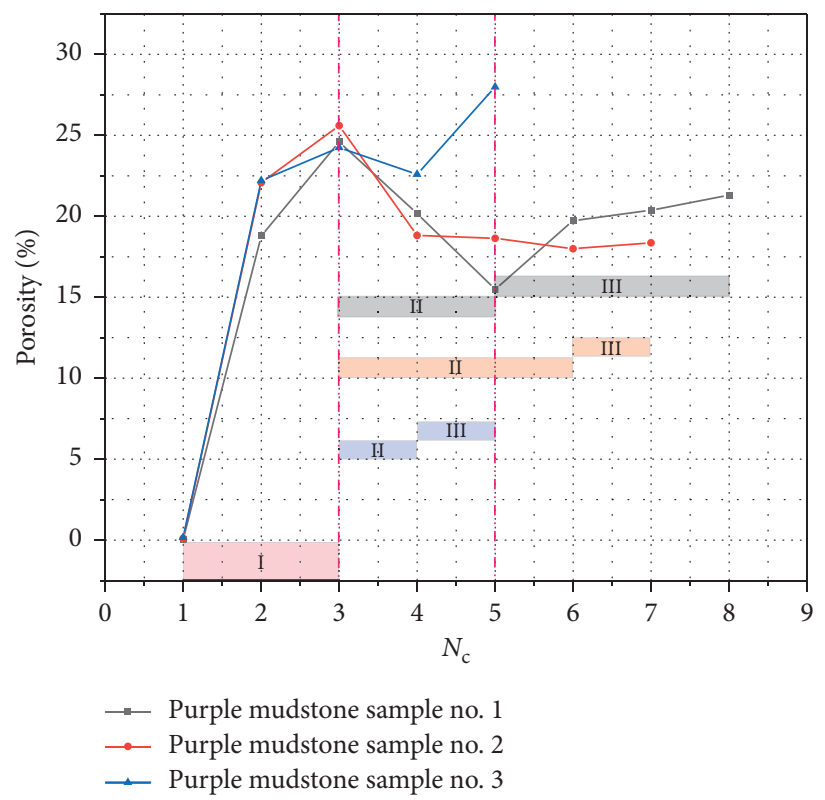

FIGURE 5: The change of porosity with the number of cycles. 
not be damaged. So, it repeated that the sample is completely destroyed. Table 4 shows the specific numerical changes.

The cumulative pore volume ratio of the purple mudstone samples varied with the sample pore size for the different sample numbers and dry and wet cycle periods (Figure 6). When the dry and wet cycle $N_{\mathrm{C}}$ was 1 , the pore distributions of the purple mudstone samples No. 1, No. 2 and No. 3 were $0.01-0.1 \mu \mathrm{m}$. The approximate slopes of the three sample curves were 2671.92, 3361.81 and 3334.40, respectively. As the number of dry-wet cycles increased, the slopes of the three samples decreased to $150.98,149.84$ and 162.00 , respectively. In general, the higher the number of dry-wet cycles, the smoother the curve and the better the corresponding pore size grading curve.

\section{Discussion}

Previous studies have shown that changes to the pore structure are related to the mineral composition of rocks and the external conditions [33, 34]. Many factors affect the pore structure during dry-wet cycles, including water, accumulation of salt crystals, and crystal expansion. These are discussed in detail.

4.1. Influence of Water. During the dry-wet cycles, the purple mudstone samples had a small pore structure with a single pore size of $0.01-0.1 \mu \mathrm{m}$ and changes to the micropore structure of less than $0.01 \mu \mathrm{m}$. This is because the pore water and calcite and quartz in the purple mudstone interacted to cause different degrees of dissolution and the contact of the minerals with water caused potassium feldspar and sodium feldspar in the purple mudstone to decompose and form kaolinite (see equations as follows). The EDS of the purple mudstone was tested by experiments (Figure 7). $\mathrm{K}^{+}, \mathrm{Na}^{+}$, $\mathrm{Ca}_{2}{ }^{+}, \mathrm{Mg}_{2}{ }^{+}$, and other cations in the purple mudstone minerals combined with the $\mathrm{OH}$ - ions in the solution and the original minerals were broken down to form new minerals. Under hydrolysis, the $\mathrm{KOH}$ solution $(\mathrm{K}+\mathrm{com}-$ bined with $\mathrm{OH}-)$ and $\mathrm{NaOH}$ solution $(\mathrm{Na}+$ combined with $\mathrm{OH}-$ ) were formed with the loss of water. The incomplete hydrolysis of the initial mineral caused the porosity in the purple mudstone to increase, resulting in new micropores smaller than $0.01 \mu \mathrm{m}$. With the progress of hydrolysis, the minerals were completely decomposed; therefore, the pores with a pore diameter of $0.01-0.1 \mu \mathrm{m}$ in the rock were decreased, and the proportion of large pores of $0.1-1 \mu \mathrm{m}$ was increased. The $\mathrm{pH}$ test found that, as the number of dry-wet cycles increased, the solution became more and more alkaline, which confirmed the occurrence of water and rock chemistry (Figure 8). Thus, various minerals in the rocks were damaged by the water-rock chemistry due to the chemical imbalance between the rocks and minerals. During this time, new micropores were generated, and the rock became loose and fragile, which was mainly manifested by the increase of pores in the purple mudstone samples that is consistent with the research findings of Feng et al. [35]. The result of the hydrochemical damage was a change of the microscopic composition of the rocks and the destruction of the original microstructure. The mechanism of geological disasters is closely related to this complex process.
4.2. Changes in Bound Water and Cumulative Crystallisation of Salt. According to Figure 9, as the number of wet-dry cycles increased, the bound water content in the sample clearly increased from $0.08876,0.25918$, and 0.3631 to 0.922 , 1 , and 0.9937 . Table 5 shows the specific numerical changes.

The existence of pore water in porous materials can be roughly divided into three types: bound water, pore water, and large amounts of free water $[1,36]$. Mudstone contains a lot of clay minerals. When water penetrates into the pores and cracks of mudstones, the adsorbed water film (bound water content) of the fine clay minerals will thicken, which will cause volumetric expansion of rock particles [37]. Bound water mainly refers to water adsorbed on the surfaces of minerals or to interlayer water when clay minerals exist [38]. The T2 spectrum of pore water in a constant-temperature uniform magnetic field is mainly determined by ion surface relaxation $[27,39]$, which mainly depends on the nature of the liquid and its affinity for the mineral surface or inner surface [40], so the quantification of pore water can be derived from the T2 spectrum. The T2 of bound water in porous materials is generally less than $3 \mathrm{~ms}$, while the range for capillary water is $3-33 \mathrm{~ms}$, while values $>33 \mathrm{~ms}$ indicate a large amount of free water [41, 42]. In this study, we used the above two critical values to divide the pore water component. The bound water content increases as the number of cycles increases. This is because the clay minerals first hydrate and swell upon encountering water. The cations between the layers combine with the water penetrating the surfaces of the minerals, causing the crystal lattice of the clay minerals to expand. In the dry state, cations are adsorbed on the surfaces of clay minerals and the interlayer spacing is almost zero. After adsorbing 1-4 layers of water molecules, the interlayer spacing expands to $12.6-21.6 \AA$, which is approximately $1 \mathrm{~nm}$ [43]. When the interlayer spacing is expanded to $3 \mathrm{~nm}$, the clay minerals enter the electric double layer and expand. Gouy-Chapman proposed that the cations adsorbed on the crystal layer of clay minerals will diffuse around them due to the increase in the thickness of the combined water film. These cations are attracted by the negative charges of their own crystal layer and, at the same time, are far away from the crystal layer due to Brownian motion. The potential energy of the layer makes the negatively charged crystal layer and the cations in the water form a diffuse electric double layer. Clay minerals undergo hydration when in contact with water, and the forces generated by the expansions of the lattice and electric double layer drive the expansion and deformation of the clay bricks. The increase in bound water proves the influence of clay minerals on the pore structure. The mechanism of influence of salt crystallisation and clay mineral swelling on the pore structure is shown in Figure 10.

Salt crystallisation is the main damage mechanism of rocks. Growing crystals can apply pressure in porous materials [44-46]. Experiments by Balboni [47]; Rivas [48]; Benavente [49]; and Bradley [50] have shown that growing crystals can exert pressure inside the rock.

During saturation of the purple mudstone, the $\mathrm{Cl}$-in the water combined with the $\mathrm{Na}^{+}$in the rocks to form $\mathrm{NaCl}$ (i.e., salt). As shown in Figure 10, fine salts were 
TABle 4: Porosity values of different cycles.

\begin{tabular}{lccc}
\hline Rock samples & Purple mudstone sample no. 1 & Purple mudstone sample no. 2 & Purple mudstone sample no. 3 \\
\hline Cycles & & Porosity (\%) & 0.15882 \\
$N_{\mathrm{c}}=1$ & 0.0122 & 0.09211 & 22.19704 \\
$N_{\mathrm{c}}=2$ & 18.78117 & 22.07175 & 24.24514 \\
$N_{\mathrm{c}}=3$ & 24.58577 & 25.59275 & 22.58676 \\
$N_{\mathrm{c}}=4$ & 20.17361 & 18.80871 & 27.98095 \\
$N_{\mathrm{c}}=5$ & 15.48541 & 18.63617 & - \\
$N_{\mathrm{c}}=6$ & 19.7253 & 17.98795 & - \\
$N_{\mathrm{c}}=7$ & 20.36575 & 18.3578 & - \\
$N_{\mathrm{c}}=8$ & 21.299 & - & - \\
\hline
\end{tabular}

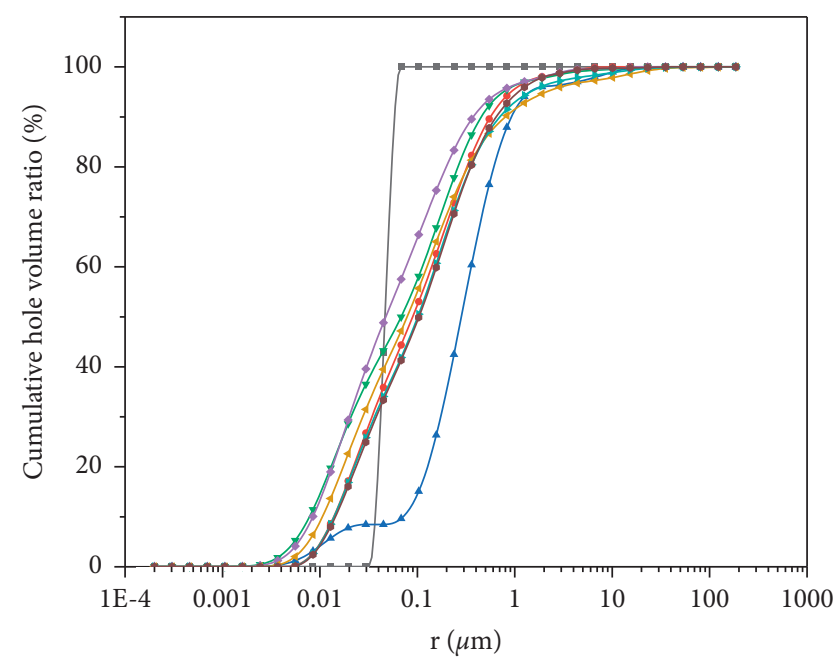

Purple mudstone sample no. 1

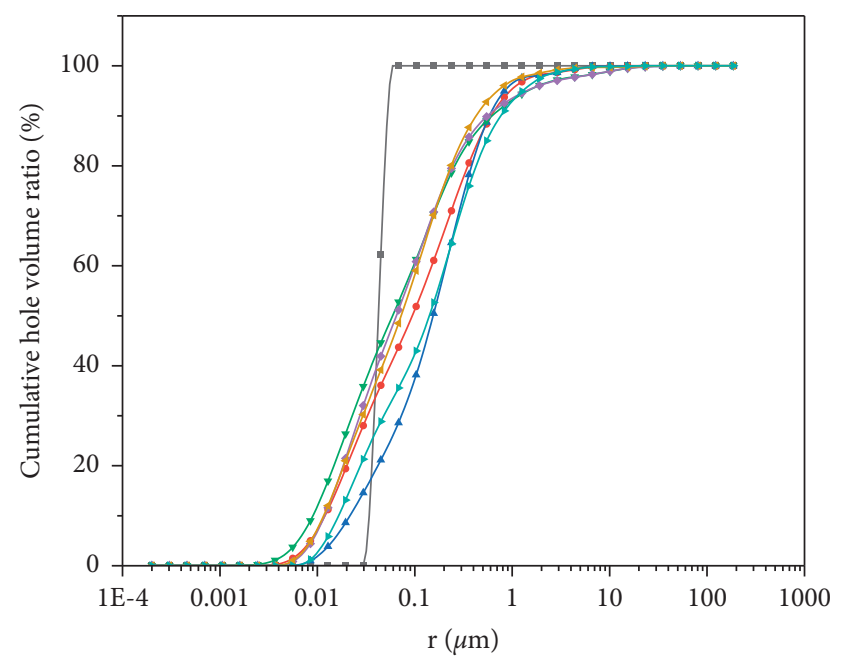

Purple mudstone sample no. 2 $\rightarrow N_{\mathrm{C}}=5$
$\because N_{\mathrm{C}}=6$
$\rightarrow N_{\mathrm{C}}=7$

$\therefore N_{\mathrm{C}}=5$

$\because N_{\mathrm{C}}=6$

$\rightarrow N_{C}=7$

$\rightarrow N_{\mathrm{C}}=4$

$\because N_{\mathrm{C}}=8$

(a)

(b)

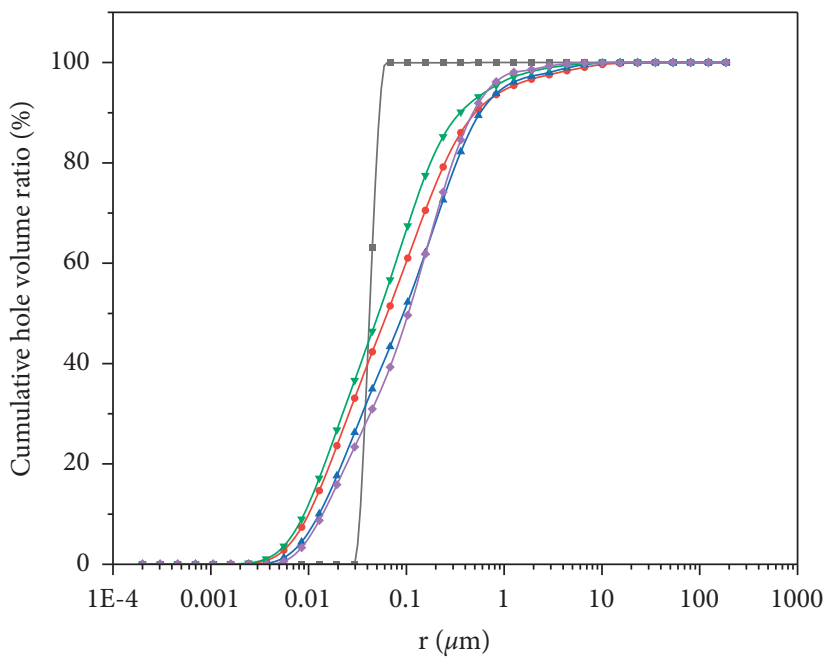

Purple mudstone sample no. 3

$\begin{array}{ll}\rightarrow N_{\mathrm{C}}=1 & \rightarrow N_{\mathrm{C}}=4 \\ \rightarrow N_{\mathrm{C}}=2 & \rightarrow N_{\mathrm{C}}=5\end{array}$

(c)

Figure 6: Cumulative pore volume ratio: (a) samples No. 1 Cumulative pore volume; (b) samples No. 2 Cumulative pore volume; (c) samples No. 3 Cumulative pore volume. 

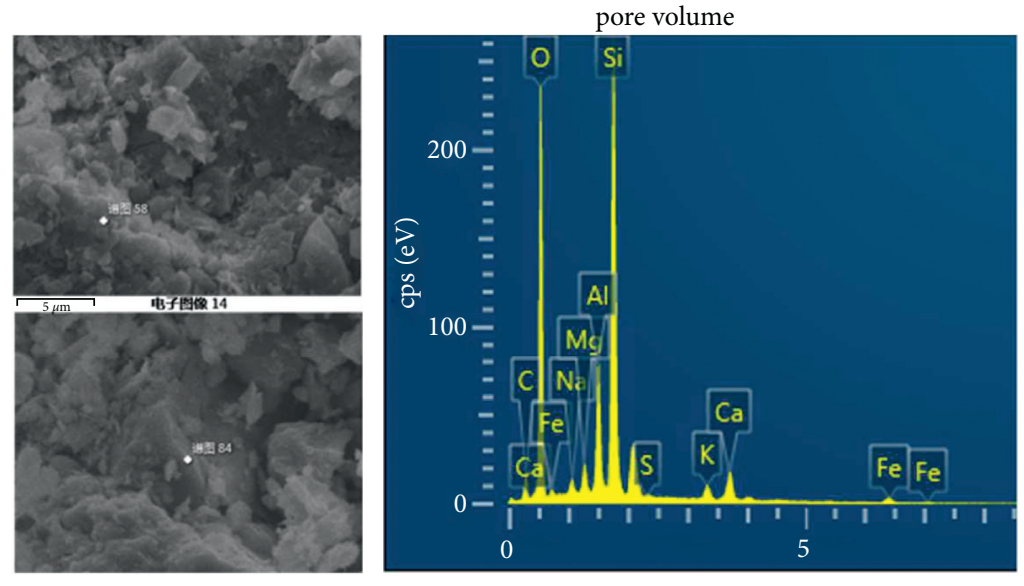

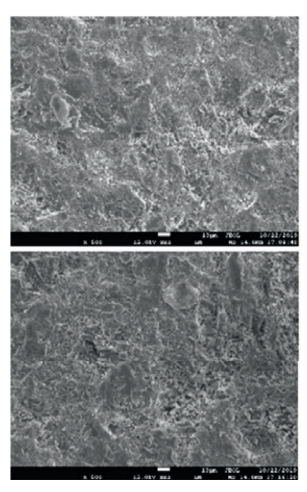

$500 \times$
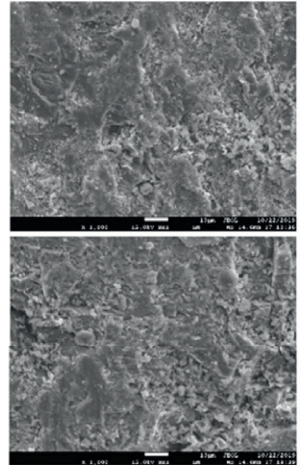

$1000 \times$

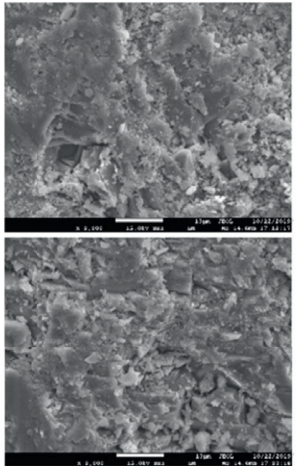

$2000 x$

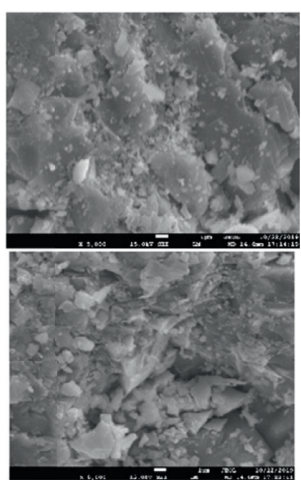

$5000 \times$

FIGURE 7: Proportion diagram of EDS experimental elements and SEM images of purple mudstone before and after dry-wet cycle.

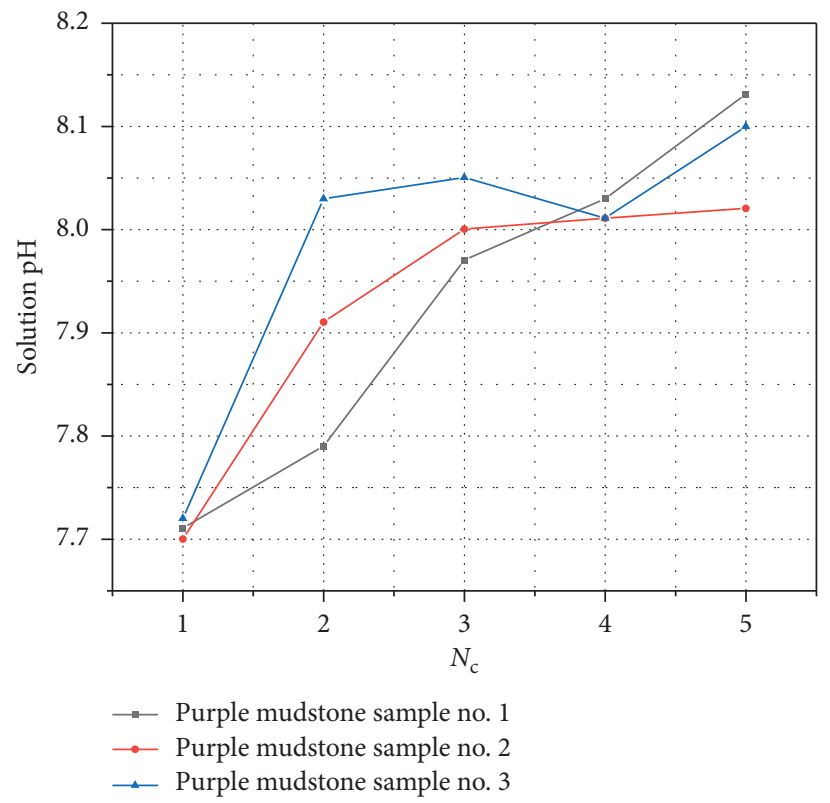

FIGURE 8: Relationship curves between the $\mathrm{pH}$ value and dry-wet cycle periods.

loosely distributed among the pores during the initial stage. As the cyclic period increased, the salt crystals in the pores increased, which caused the NMR test results in the present study to change from a single peak with a distribution interval of $0.01-1 \mu \mathrm{m}$ to a double peak with a distribution interval of $0.001-0.1 \mu \mathrm{m}$. When accumulated to a certain degree, the salt will squeeze against itself, causing stress on the inner wall of the rock hole. The 


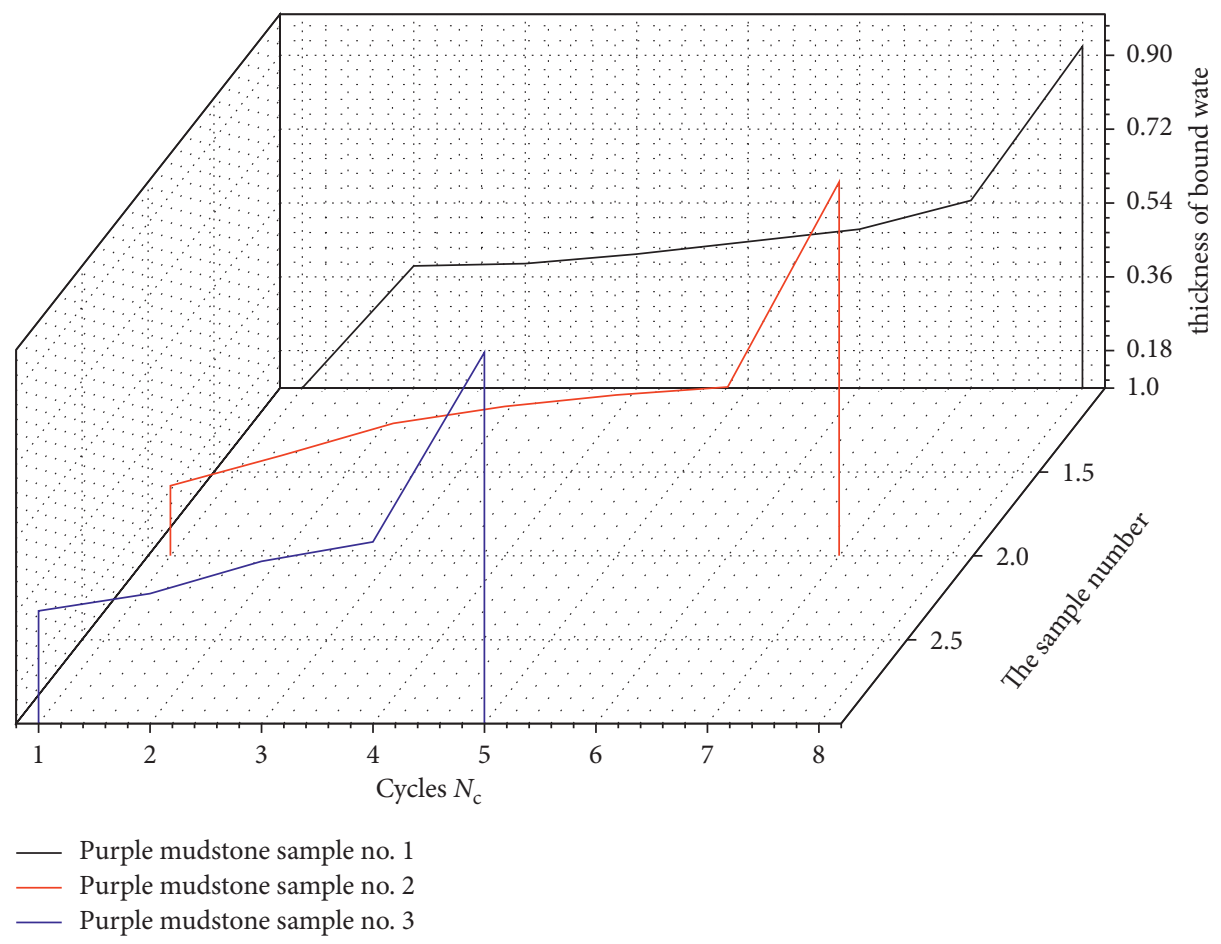

FIGURE 9: Diagram of the variation of irreducible water thickness with the number of dry and wet cycles.

TABLE 5: The bound water thickness of different cycles.

\begin{tabular}{lccc}
\hline Rock samples & Purple mudstone sample no. 1 & Purple mudstone sample no. 2 & Purple mudstone sample no. 3 \\
\hline Cycles & & Thickness of bound water & 0.3631 \\
$N_{\mathrm{c}}=1$ & 0.08876 & 0.25918 & 0.40547 \\
$N_{\mathrm{c}}=2$ & 0.38616 & 0.33331 & 0.48394 \\
$N_{\mathrm{c}}=3$ & 0.39193 & 0.41139 & 0.53167 \\
$N_{\mathrm{c}}=4$ & 0.41535 & 0.45259 & 0.9937 \\
$N_{\mathrm{c}}=5$ & 0.44548 & 0.48053 & - \\
$N_{\mathrm{c}}=6$ & 0.47607 & 0.50031 & - \\
$N_{\mathrm{c}}=7$ & 0.54615 & 0.98669 & - \\
$N_{\mathrm{c}}=8$ & 0.92168 & - & - \\
\hline
\end{tabular}

accumulation of salt crystals causes this stress to increase and the pores to become enlarged. This explains the increase in the proportion of large pores with a total pore diameter of $0.1-1 \mu \mathrm{m}$ in the NMR test results in the present study.

4.3. Crystal Expansion. The purple mudstone samples withstood a temperature of $60^{\circ} \mathrm{C}$ during the drying process, whereas rocks have stresses between $20^{\circ} \mathrm{C}$ and $90^{\circ} \mathrm{C}$ [51]. Rock is not a good thermal conductor; therefore, the surface temperature will be significantly different from the temperature inside the rock. Any expansion experienced during high-temperature heating will cause crushing of the outer layer of stones. This produced micropores smaller than $0.01 \mu \mathrm{m}$. Immediately after the rock was heated, it was placed into water, which caused thermal shock to increase the damage. The water quickly cooled the hot purple mudstone samples, causing further spalling and making the pores bigger, with pores larger than $0.1 \mu \mathrm{m}$ being produced. Crystal expansion is the main mechanism for the deterioration of rock properties [52]. The calcite from the purple mudstone samples in the present study accounted for $3 \%-6 \%$. Calcite is a mineral that expands in one direction and contracts in the other direction when heated (Figure 11). As it cools, it will shrink along the c-axis while expanding along the other axes. Therefore, calcite is very vulnerable to thermal cycling [53]. The results of mathematical modelling have shown that calcite is susceptible to thermal weathering [51]. For calcite, the stress caused by heating to $40-50^{\circ} \mathrm{C}$ causes cracks, resulting in the appearance of new micropores with a pore size of less than $0.01 \mu \mathrm{m}$. Heating causes cracking and increased porosity [54], increasing the proportion of large pores with a pore size of $0.1-1 \mu \mathrm{m}$. 

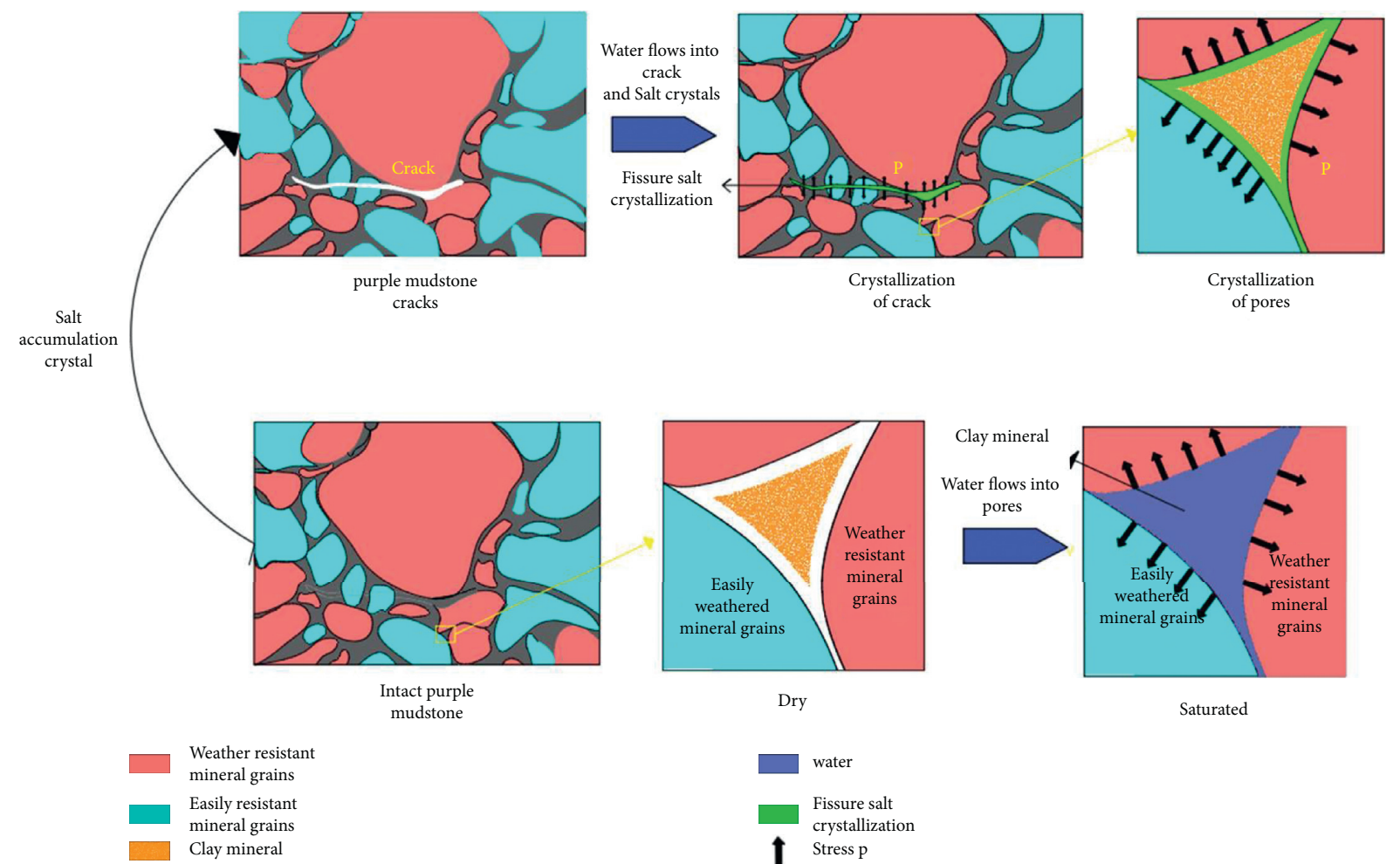

FIGURE 10: Mechanism of clay mineral swelling and cumulative crystallisation of salt.

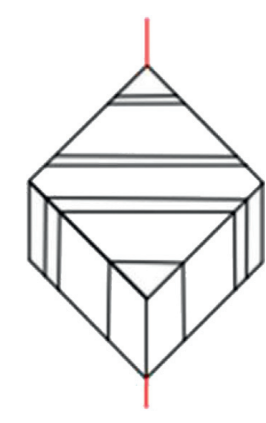

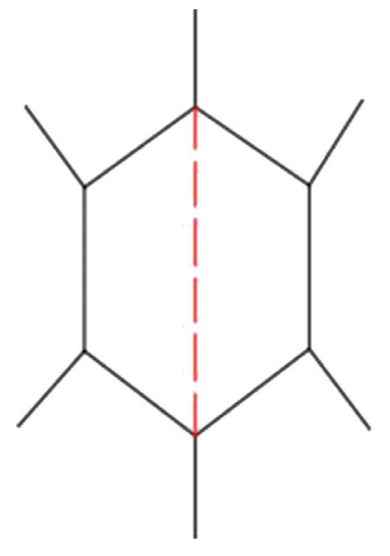

(b)

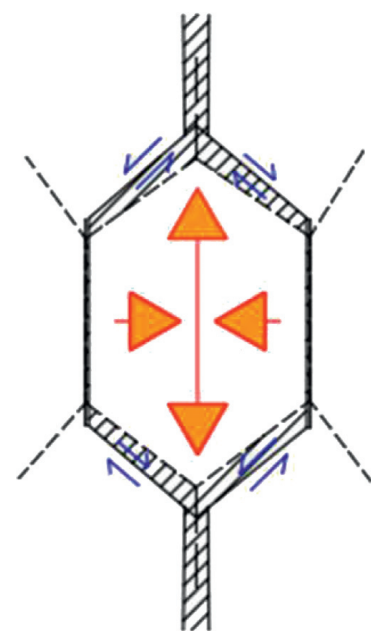

(c)

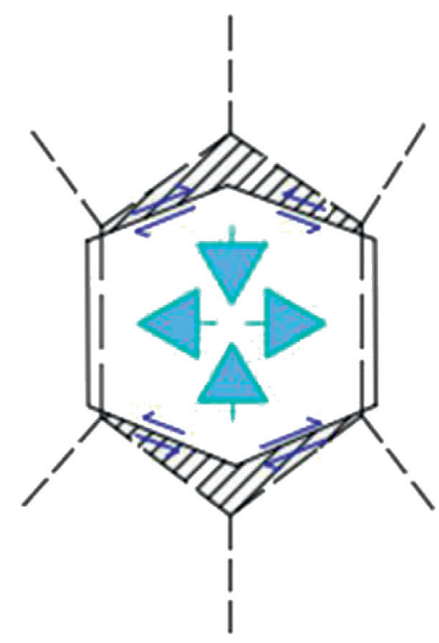

(d)

FIGURE 11: Calcite expansion and contraction process. (a) Single crystal (b) initial (c) expansion and contraction by heat (d) expansion and contraction by cold.

\section{Conclusion}

The present study aimed to examine the changes in the porosity of purple mudstone samples under multiple drywet cycle conditions. The following results were obtained:

(1) With an increase in the number of dry-wet cycles, the purple mudstone pore volume ratio significantly changed. Originally, it consisted of a small pore structure with a single pore diameter of $0.01-0.1 \mu \mathrm{m}$ and changed to a variety of pore structures with various pore diameters of $0.001-100 \mu \mathrm{m}$.

(2) With the increase in the number of dry-wet cycles, the micropores $(0.001-0.1 \mu \mathrm{m})$ were transformed into macropores $(0.1-1 \mu \mathrm{m})$. The proportion of small pores decreased from $17.50 \%$ to $56.32 \%$, whereas the proportion of large pores increased from $8.56 \%$ to $15.00 \%$. The area of the first peak (micropores $0.001-0.1 \mu \mathrm{m}$ ) of sample nos. 1,2 , and 3 decreased 
from $0.1277,0.1181$, and 0.1376 to $0.1209,0.1047$, and 0.1245 , respectively. The area of the second peak of the three samples (large pores $0.1-1 \mu \mathrm{m}$ ) increased from $0.9413,0.9974$, and 0.6779 to $0.9871,1.1498$, and 0.9901 , respectively.

\section{Data Availability}

No data, models, or code were generated or used during the study.

\section{Conflicts of Interest}

The authors declare that they have no conflicts of interest.

\section{Acknowledgments}

This research was supported by the National Natural Science Foundation of China (Grant nos.41672279 and 41807233). The authors also thank the technicians who helped during the experiments.

\section{References}

[1] Q. Sun and Y. L. Zhang, "Combined effects of salt, cyclic wetting and drying cycles on the physical and mechanical properties of sandstone," Engineering Geology, vol. 248, 2018.

[2] W. Yao, C. Li, H. Zhan, J. Q. Zhou, and X. Jiang, "Multiscale study of physical and mechanical properties of sandstone in three gorges reservoir region subjected to cyclic wettingdrying of yangtze river water," Rock Mechanics and Rock Engineering, vol. 1, 2020.

[3] X. Huang, J. Pang, G. Liu, and H. Rodrigues, "Experimental Study on Physicomechanical Properties of Deep Sandstone by Coupling of Dry-Wet Cycles and Acidic Environment," Advances in Civil Engineering, vol. 2020, Article ID 2760952, 17 pages, 2020

[4] Y. Yao, D. Liu, Y. Che, D. Tang, S. Tang, and W. Huang, "Petrophysical characterization of coals by low-field nuclear magnetic resonance (nmr)," Fuel, vol. 89, no. 7, pp. 1371-1380, 2010.

[5] W. X. Ding and X. T. Feng, "Study on chemical damage effect and quantitative analysis method of meso-structure of limestone," Journal of rock mechanics and engineering, vol. 024, no. 008, pp. 1283-1288, 2005.

[6] N. Li, Y. Zhu, and B. Su, "A chemical damage model of sandstone in acid solution," International Journal of Rock Mechanics and Mining Science, vol. 40, no. 2, pp. 243-249.

[7] G. Pardini, G. V. Guidi, R. Pini, D. Regüés, and F. Gallart, "Structure and porosity of smectitic mudrocks as affected by experimental wetting-drying cycles and freezing-thawing cycles," Catena, vol. 27, no. 3-4, pp. 0-165, 1996.

[8] P. D. Sumner and M. J. Loubser, "Experimental sandstone weathering using different wetting and drying moisture amplitudes," Earth Surface Processes and Landforms, vol. 33, no. 6, 2008.

[9] A. Oezbek, "Investigation of the effects of wetting-drying and freezing-thawing cycles on some physical and mechanical properties of selected ignimbrites," Bulletin of Engineering Geology and the Environment, vol. 73, no. 2, pp. 595-609, 2014.
[10] A. Mohamed and A. W. Kassab, "Study on P-wave and S-wave velocity in dry and wet sandstones of Tushka region, Egypt," Egyptian Journal of Petroleum, vol. 24, no. 1, 2015.

[11] G. Khanlari and Y. Abdilor, "Influence of wet-dry, freeze-thaw, and heat-cool cycles on the physical and mechanical properties of upper red sandstones in central Iran," Bulletin of Engineering Geology and the Environment, vol. 74, no. 4, pp. 1287-1300, 2015.

[12] X. R. Liu, Y. Fu, Y. X. Zhang, Y. X. Hu, and Y. K. Xie, “A review on deterioration of rock caused by water-rock interaction," Hydrogeology Engineering Geology, no. 06, pp. 60-64, 2009.

[13] Z. Zhou, X. Cai, L. Chen, W. Cao, Y. Zhao, and C. Xiong, "Influence of cyclic wetting and drying on physical and dynamic compressive properties of sandstone," Engineering Geology, vol. 220, pp. 1-12, 2017.

[14] S. Tao, S. D. Chen, D. Z. Tang, X. Zhao, H. Xu, and S. Li, "Material composition, pore structure and adsorption capacity of low-rank coals around the first coalification jump: a case of eastern Junggar Basin, China," Fuel, vol. 211, pp. 804-815, 2018.

[15] F. Tao, L. Zhang, N. Liu et al., "Quantitative characterization of pore structure of the carboniferous-permian tight sandstone gas reservoirs in eastern linqing depression by using nmr technique," Petroleum Research, vol. 3, pp. 110-123, 2018.

[16] Z. Jian, H. Deng, T. Abbas, K. Bo, C. Liu, and X. Yang, "Degradation of physical and mechanical properties of sandstone subjected to freeze-thaw cycles and chemical erosion," Cold Regions Science and Technology, vol. 155, pp. 37-46, 2018.

[17] Z. J. Wang, X. R. Liu, Y. Fu, L. Zhang, and W. Yan, "Study on degradation of mechanical parameters of argillaceous sandstone by dry and wet cycling in acidic environment," Journal of geotechnical engineering, no. 6, pp. 1152-1159, 2016.

[18] L. Xinrong, W. Zijuan, F. Yan, Y. Wen, and M. Luli, "Macro/ microtesting and damage and degradation of sandstones under dry-wet cycles," Advances in Materials Science and Engineering, vol. 2016, pp. 1-16, 2016.

[19] W. Looyestijn and J. Hofman, "Wettability-index determination by nuclear magnetic resonance," SPE Reservoir Evaluation and Engineering, vol. 9, no. 2, pp. 146-153, 2006.

[20] Y. He, Z. Mao, L. Xiao, and X. Ren, "An improved method of using nmr $\mathrm{t} 2$ distribution to evaluate pore size distribution," Chinese Journal of Geophysics, vol. 48, no. 002, pp. 373-378, 2005.

[21] R. L. Kleinberg, C. Straley, W. E. Kenyon, R. Akkurt, and S. A. Farooqui, "[Society of petroleum engineers SPE annual technical conference and exhibition - houston, Texas," SPE Annual Technical Conference and Exhibition - Nuclear Magnetic Resonance of Rocks: T1 vs. T2, 1993.

[22] \& R. ., L. Kleinberg, "Seafloor nuclear magnetic resonance assay of methane hydrate in sediment and rock," Journal of Geophysical Research, vol. 108, no. B3, p. 2137, 2003.

[23] P. E. ren, F. Antonsen, and H. G. Ruesltten, Numerical Simulations of NMR Responses for Improved Interpretations of NMR Measurements in Reservoir Rocks, Society of Petroleum Engineers, San Antonio, Texas, 2002.

[24] H. Xu, Y. Fan, F. Hu et al., "Characterization of pore throat size distribution in tight sandstones with nuclear magnetic resonance and high-pressure mercury intrusion," Energies, vol. 12, 2019.

[25] A. R. Tice, D. M. Anderson, and K. F. Sterrett, "Unfrozen water contents of submarine permafrost determined by 
nuclear magnetic resonance," Developments in Geotechnical Engineering, vol. 28, pp. 135-146, 1982.

[26] K. Watanabe and T. Wake, "Measurement of unfrozen water content and relative permittivity of frozen unsaturated soil using NMR and TDR," Cold Regions Science and Technology, vol. 59, no. 1, pp. 34-41, 2009.

[27] R. Dastidar, "Nuclear Magnetic Resonance (NMR) Study of Freezing and Thawing of Saturated Porous media and Application to Shale and Pore Volume Compressibility Estimation," Doctoral dissertation, 2007.

[28] T. Liu, C. Zhang, K. Zhou, and Y. Tian, "Freeze-thaw cycling damage evolution of additive cement mortar," European Journal of Environmental and Civil Engineering, vol. 25, 2019.

[29] L. Tang, Y. Du, and L. Liu, "Effect mechanism of unfrozen water on the frozen soil structure interface during the freezing-thawing process," Geomech. Eng., 2020.

[30] G. Fang and Y. C. Xia, "Prevention and control technology of water during mining extremely thick coal seam with thin rock roof under ditch in chaigou coal mine," Journal of Xi'an University of Science and Technology, 2018.

[31] J. W. Mao, G. Q. Xie, Z. H. Zhang, X. F. Li, and Y. F. Li, "Mesozoic large-scale metallogenic pulses in north china and corresponding geodynamic setting," Acta Petrologica Sinica, vol. 21, no. 1, pp. 169-188, 2005.

[32] Y. Gong, S. Liu, M. Zhao, H. Xie, and K. Liu, "Characterization of micro pore throat radius distribution in tight oil reservoirs by nmr and high pressure mercury injection," Petroleum Geology \& Experiment, vol. 38, no. 3.

[33] A. Turul, "The effect of weathering on pore geometry and compressive strength of selected rock types from Turkey," Engineering Geology, vol. 75, no. 3, pp. 215-227, 2004.

[34] R. Rezaee, A. Saeedi, and B. Clennell, "Tight gas sands permeability estimation from mercury injection capillary pressure and nuclear magnetic resonance data," Journal of Petroleum Science and Engineering, vol. 88-89, 2012.

[35] X. T. Feng, S. J. Li, and S. L. Chen, "Effect of water chemical corrosion on strength and cracking characteristics of rocks - a review," Key Engineering Materials, vol. 261-263, pp. 1355-1360, 2004.

[36] G. R. Coates, J. Galford, D. Mardon, and D. Marschall, “A new characterization of bulk-volu me irreducible using magnetic resonance," The. Log. Analyst.vol. 39, no. 01, 1998.

[37] N. Zhang, F. Zhao, S. Wang, L. I. Jiabin, and D. Sun, "Review of nuclear magnetic resonance technique based study on pore structure and seepage characteristics of rock," Water Resources and Hydropower Engineering, 2018.

[38] H. Jia, S. Ding, Y. Wang, F. Zi, and Q. Sun, "An nmr-based investigation of pore water freezing process in sandstone," Cold Regions Science and Technology, vol. 168, Article ID 102893, 2019.

[39] B. P. Cowan, Nuclear Magnetic Resonance and Relax at Ion, Cambridge University Press, Cambridge, UK, 1997.

[40] S. Godefroy, J.-P. Korb, M. Fleury and R G. Bryant, Surface nuclear magnetic relaxation and dynamics of water and oil in macroporous media," Physical Review, vol. 64, no. 2, Article ID 21605, 2001.

[41] A. Matteson, J. P. Tomanic, M. M. Herron, D. F. A llen, and W. E. Kenyon, "NMR relax at ion of clay-brine mix tu res," SPE Annual Technical Conference and Ex H Ibit Ion, vol. 3, pp. 205-211, 1998.

[42] G. A. Martinez and L. A. Davis, "Petrophysical measurements on shales using NMR," SPE/AAPG Western Regional Meeting, 2000 .
[43] K. Norrish, "Manner of Swelling of Montmorillonite," Nature, 1954.

[44] H. De Clercq, "The effect of other salts on the crystallization damage to stone caused bysodium sulphate," Salt Weathering on Buildings and Stone Sculptures, Technical Universityof Denmark, Lyngby, 2008.

[45] I. S. I. S. S. Evans, "Salt crystallization and rock weathering: a review," Revue Geomorph Dynam, vol. 19, no. 6, pp. 153-177, 1970.

[46] W. S. Ginell, "The nature of changes caused by physical factors," in Durability and Change. The science, responsibility and cost of sustaining the cultural heritage Krumbein, Krumbein WE, 1994.

[47] E. Balboni, R. M. Espinosa-Marzal, E. Doehne, and G. W. Scherer, "Can drying and re-wetting of magnesium sulfate salts lead to damage of stone?" Environmental Earth Sciences, vol. 63, no. 7-8, pp. 1463-1473, 2011.

[48] T. Rivas, B. Prieto, J. M. Birginie, and F. Auger, "Granite Decay by a marine Salt-spray Accelerated Ageing Test," 2002.

[49] D. Benvaenter, "Thermodynamic modelling of changes induced by salt pressure crystallisation in porous media of stone," Journal of Crystal Growth, vol. 204, no. 1-2, pp. 168-178, 1999.

[50] W. C. Bradley, J. T. Hutton, and C. R. Twidale, "Role of salts in development of granitic Tafoni, South Australia," The Journal of Geology, vol. 86, no. 5, pp. 647-654, 1978.

[51] T. Weiss, D. Strohmeyer, D. Kirchner, J. Sippel, and S. Siegesmund, "Weathering of stonescaused by thermal expansion, hygric properties and freeze-thaw cycles," in Proceedings of the 10th International congress on Deterioration Andconservation of Stone, D. Kwiatkowski and Löfvendahl, Eds., pp. 83-90, ICOMOS, Sweden, Stockholm, 2004.

[52] T. Wangler and G. W. Scherer, "Clay swelling mechanism in clay-bearing sandstones," Environmental geology and water ences, vol. 56, no. 3-4, pp. 529-534, 2008.

[53] M. Franzini, C. Gratziu, and M. Spampinato, "Degradazione del marmo per effetto di variazionedi temperatura," Rend Soc It Min Petrol, vol. 39, pp. 47-58, 1984.

[54] K. Malaga-Starzec, J. E. Lindqvist, and B. Schouenborg, "Experimental study on the variation in porosity of marble as a function of temperature," Geological Society London Special Publications, vol. 205, no. 1, pp. 81-88, 2002. 